\title{
Knowledge, Attitude and Practices towards Lifestyle Disorders in Rural Communities, in Maharashtra, India
}

\author{
Prajakta Prakash Jadhav르, Anushka Nitin Kamble ${ }^{2}$, Suraj Bhimarao Kanase ${ }^{3}$, Dhiraj Kumar Mane \\ 1, 2, 3, 4 Department of Physiotherapy, Krishna Institute of Medical Sciences \\ (Deemed to Be University), Karad, Maharashtra, India.
}

\section{ABSTRACT}

\section{BACKGROUND}

Lifestyle is a way of living which depends on geographical, cultural, social, economic, political, and religious characteristics. An individual's lifestyle is defined by many factors such as his daily physical activities, diet, nutrition, stress, alcohol consumption, drug abuse, smoking, sleep etc. Disorder means disruption in the normal physical or mental functioning of body. Lifestyle disorders are disorders related with way one lives his life. Lifestyle disorders include cardiovascular diseases, musculoskeletal diseases, stroke, depression, chronic obstructive lung disease, diabetes mellitus, chronic respiratory disease, and certain types of cancers like lung cancer, cervical cancer etc. Risk factors for lifestyle disorders are physical inactivity, excessive use of alcohol, smoking, wrong body posture, obesity, unhealthy diet. The focus of this study was to determine the knowledge, attitude and practices in the rural communities towards lifestyle disorders.

\section{METHODS}

This observational study was conducted among 394 participants aged between 20 and 45 years who were selected from Malkapur, Karad, through simple random sampling method. Out of 394 subjects, 181 were males and 213 were females. A structured questionnaire which involved 30 questions based on knowledge, attitude and practices regarding lifestyle disorders was used in this study.

\section{RESULTS}

In this study it was found that, out of 394 participants, $34 \%$ (132) participants had good knowledge regarding lifestyle disorders, $18 \%$ (70) participants had positive attitude towards lifestyle disorders and only $13 \%$ (61) participants were actually practicing healthy habits ( $\mathrm{P}$-value $=<0.0001$ ). After comparison between two age groups 20 - 32 years (181) and $33-45$ years (213) it was indicated that there was significant association between the practice score with P-value of 0.0004 and chi square value of 15.45 .

\section{CONCLUSIONS}

Above study concluded that the participants had adequate knowledge about lifestyle disorders, but they lacked positive attitude and healthy practices towards lifestyle disorders.

\section{KEY WORDS}

Lifestyle Disorders, Knowledge, Attitude, Practices
Corresponding Author: Dr. Suraj Bhimarao Kanase, Department of Physiotherapy, Krishna Institute of Medical Sciences "Deemed to Be University", Karad, Maharashtra, India. E-mail: drsurajkanase7@rediffmail.com

DOI: $10.14260 / \mathrm{jemds} / 2021 / 290$

How to Cite This Article: Jadhav PP, Kamble AN, Kanase SB, et al. Knowledge, attitude and practices towards lifestyle disorders in rural communities in Maharashtra, India. J Evolution Med Dent Sci 2021;10(19):1372-1376, DOI: $10.14260 /$ jemds/2021/290

Submission 05-01-2021,

Peer Review 11-03-2021,

Acceptance 17-03-2021,

Published 10-05-2021.

Copyright (C) 2021 Prajakta Prakash Jadhav et al. This is an open access article distributed under Creative Commons Attribution License [Attribution 4.0 International (CC BY 4.0)] 


\section{BACKGROUND}

Lifestyle is a way of living of residents of region which depends on geographical, cultural, social, economic, political, and religious characteristics. Lifestyle disorders are the acquired disorders due to day-to-day habits which distract the people from healthy habits and push them towards detrimental lifestyle. ${ }^{1}$ Lifestyle disorders include stroke, diabetes mellitus, atherosclerosis, obesity, hypertension, chronic obstructive pulmonary diseases, chronic liver diseases, cirrhosis, asthma, nephritis, musculoskeletal disorders, cardiovascular diseases etc. Diet, stress level in his or her life, obesity, drug abuse, lack of exercise, alcohol consumption, smoking, sedentary working hours and high cholesterol levels are modifiable risk factors for lifestyle disorders. Age, gender, race / ethnic background and genetic predisposition are non-modifiable risk factors. World Health Organization (WHO) states that cardiovascular diseases, stroke, obesity, cancer, diabetes, respiratory disease account for $60 \%$ death per year globally. ${ }^{2}$ According to the WHO fact report 2018, the non-communicable diseases caused 41 million deaths each year, as per them that is equivalent to $71 \%$ of global deaths. Lifestyle disorders are the largest and the leading cause of death in developing countries. Ischemic heart disease is the most common lifestyle disorder which accounts for $30 \%$ death globally and nearly $80 \%$ death took place in low and middle-income countries like India. ${ }^{3}$ Stroke prevalence has been increased in India (194 - 215 per 100,00 population) while the developed countries experience a $42 \%$ drop in the incidence of stroke. Stroke has become the $3^{\text {rd }}$ leading cause of death and disability in India. ${ }^{4}$ Recent studies show that out of the total stroke patients in India, $10 \%$ to 15 $\%$ of the stroke patients were below the age of 40 years. ${ }^{5}$ Hypertension and diabetes mellitus were common risk factors in older age groups while smoking, alcohol and drug intake were more common in young age in case of stoke. ${ }^{6}$ Obesity has adverse effects on health and negative impact on the proper functioning of body. ${ }^{7}$ The prevalence of obesity depends on the geographic factors and physical activities of the individual.

Lifestyle disorders affects the entire family in financial, emotional, and psychological way which ultimately affects the society and community because of reduced levels of productivity for a functionally impaired person, higher cost of health care. ${ }^{8}$ In India, $50 \%$ of families with member of cancer and $25 \%$ of families with member of cardiovascular diseases experiences catastrophic expenditure and are driven to poverty. ${ }^{9}$ Hospital stays have also been increased in the past few decades due to non-communicable diseases which ultimately have financial load on family. Economic burden in the range of $5 \%-10 \%$ of gross domestic product (GDP) is reported due to non-communicable diseases in India, which indirectly creates huge impact on the developmental strategies. ${ }^{10}$ Lifestyle disorders are the leading cause of death and disability in developing countries like India which indirectly creates a lot of economic burden on the Government of India in various ways.

In rural population, literacy rate is lower than urban population. The availability of health care system is lacking in rural areas and they approach to the health care which is close to home irrespective of quality of treatment like traditional healers is considered as first level of treatment by rural community. ${ }^{11,12}$
The focus of this study was to determine the percentage of knowledge, attitude, and practices in the rural communities towards lifestyle disorders.

\section{METHODS}

This was an observational study conducted among 394 participants with age group between 20 - 45 years. Study duration was 6 months which was from November 2019 to April 2020. The selection of participants was done by prevalence-based sample estimation using simple random sampling method from the rural population of Karad. Participants were considered according to the inclusion and exclusion criteria.

\section{Inclusion Criteria}

1. The participants with age group between 20 - 45 years.

2. Both male and females were included.

\section{Exclusion Criteria}

1. Patients with mental illness.

2. Participants who are not willing to participate are excluded.

\section{Sample Size}

Sample size was calculated by the formula $-\mathrm{n}=4 \mathrm{pq} / \mathrm{L}^{2}$ $\mathrm{n}=$ sample size

$\mathrm{p}$ = prevalence / relative population of positive knowledge, attitude and practices of population towards lifestyle $=56$. $\mathrm{q}=$ no positive knowledge, attitude and practices $=100-\mathrm{p}$ $100-56=44$

$\mathrm{L}=$ allowable error of $95 \%$ confidence interval $=5 \%$ $\mathrm{n}=\frac{4(56)(44)}{(5)^{2}}$

$\mathrm{N}=394$

(Ref - Muhamad R, Yahya R, Yusoff HM. Knowledge, attitude and practice on cardiovascular disease among women in North-East coast Malaysia. International Journal of Collaborative Research on Internal Medicine \& Public Health. 2012;4 (1):013)

Subjects were included in the study by using simple random sampling method. A structured, standardized questionnaire was used for data collection. The questionnaire included 30 questions in which there were 10 questions for each, knowledge, attitude and practices regarding lifestyle disorders.

The correct response carried 1 point and incorrect carried 0 point with highest score being 30 and lowest being 0 . This study evaluated Knowledge, Attitude and Practise (KAP) of participants in various domains including physical activity, diet, environmental factors, psychological factors, habits, and addictions.

Scoring system: As per the measures of central tendency, the scoring for knowledge, attitude and practices were as follows -

1. Knowledge: SD - 1.753 and mean - 6.69 
Good - 8 to 10

Average -6 to 7

Poor - 0 to 5

2. Attitude: SD - 1.363 and mean -5.248

Good - 7 to 10

Average - 5 to 6

Poor - 0 to 4

3. Practices: SD - 1.8 and mean- 4.68

Good -7 to 10

Average - 4 to 6

Poor - 0 to 3

The questionnaire was validated by professors from within and outside the University. Questionnaire had sensitivity and specificity of more than $80 \%$ and was then included in the study.

The sensitivity and specificity were estimated by using Cohen's kappa statistics method. Data was collected by face to face interview with the subject by using the structured questionnaire on knowledge, attitude and practices of lifestyle disorders. The study was conducted after receiving the approval from the Institutional Ethical Committee of Krishna Institute of Medical Sciences "Deemed to Be University", Karad.

\section{Statistical Analysis}

Data analysis was performed using the InStat software (GraphPad Instat 3). Results were mainly represented in percentages and frequencies. The chi-square test was used for data analysis.

\section{RESULTS}

The data of knowledge, attitude, and practices towards lifestyle disorders in rural communities was obtained from structured lifestyle disorder questionnaire as an outcome measure. Out of the total sample of 394 participants, 181 were male and 213 were female between the age group of $20-45$ years.

\begin{tabular}{|cccccccc|}
\hline \multirow{2}{*}{ Score } & \multicolumn{2}{c}{ Good } & \multicolumn{2}{c|}{ Average } & \multicolumn{2}{c|}{ Poor } & P-Value \\
& F & $\%$ & F & $\%$ & F & $\%$ & \\
Knowledge & 132 & $34 \%$ & 167 & $42 \%$ & 95 & $24 \%$ & $<0.0001$ \\
Attitude & 70 & $18 \%$ & 203 & $51 \%$ & 121 & $31 \%$ & Chi-Square Value \\
Practices & 61 & $13 \%$ & 233 & $50 \%$ & 174 & $37 \%$ & 61.261 \\
\hline \multicolumn{3}{|c|}{ Table 1. Total Score of Knowledge, Attitude and Practices. } \\
\hline *Significant when $p<0.05, F$ - Frequency, \% - percentage \\
\hline
\end{tabular}

The categorization of score (good, average, poor) was done by measures of central tendency i.e., mean, SD. The overall knowledge score suggested that $34 \%$ (132) participants had good, $42 \%$ (167) had average and $24 \%$ (95) had poor knowledge regarding lifestyle disorder with mean of 6.695 and standard deviation 1.753. The mean and standard deviation of attitude was 5.248 and 1.363 respectively. Out of 394 participants, $18 \%$ (70) had positive attitude towards lifestyle disorder. The mean and standard deviation of practices was 4.6 and 1.8 respectively. The practices followed by participants indicated that only $13 \%$ (61) were under the category of good, $50 \%$ (174) belonged to average and $37 \%$
(174) were following poor practices. The P-value was $<0.0001$ and chi square value was 61.261. (Table 1)

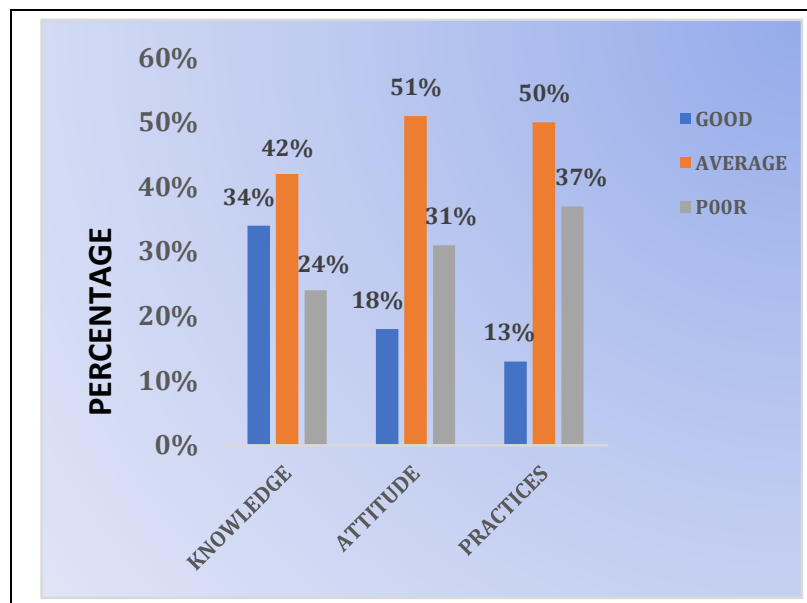

Figure 1. Total Percentage of Knowledge, Attitude and Practices
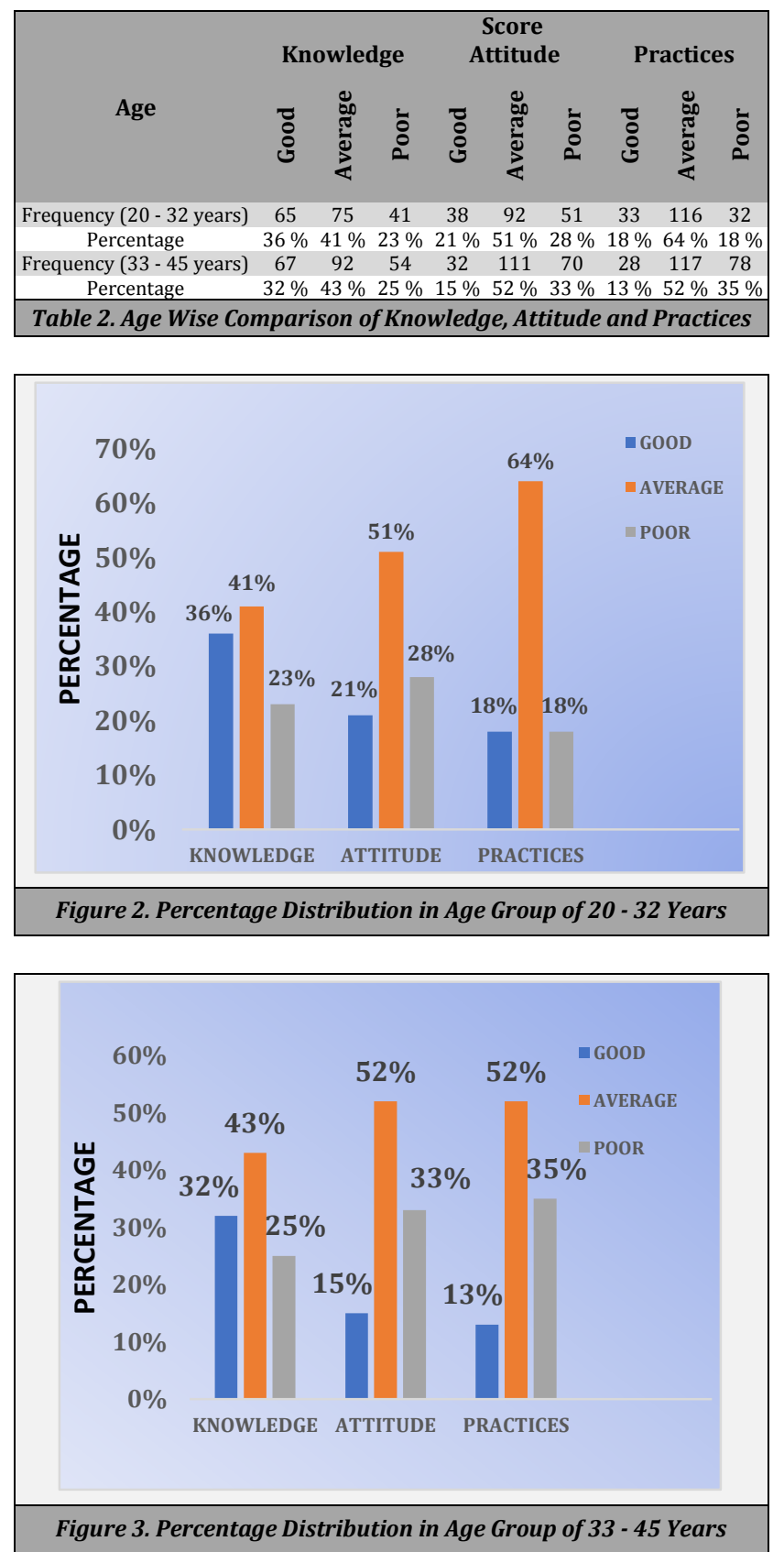
After comparison between two age groups that is up to 32 and above 32, it was indicated that there was a significant association between the practices score with P-value of 0.0004 and chi square value of 15.451 , but knowledge $(P=0.6228$ chisquare $=0.9471)$ and attitude $(\mathrm{P}=0.2599$ Chi-square $=2.695)$ score were not significantly associated. (Table 2 .)

\section{DISCUSSION}

Due to modernization of lifestyle most of the young population of the country is getting attracted to the western culture including changing of diet pattern, following a sedentary lifestyle, getting attracted towards smoking, tobacco chewing, alcohol consumption, drug addiction etc. As a result of this rapidly changing lifestyle, the burden of disorders that emerge due to unhealthy lifestyle is increasing. As the rural population is getting affected due to the modern lifestyle, the present study was conducted with an aim of screening the knowledge, attitude and practices towards lifestyle disorder including participants from rural areas of Karad. 394 participants were the sample size out of which 181 were male and 213 were female between the age group of 20 - 45 years. KAP study among rural population is vital to promote education regarding healthy lifestyle.

Thus, this study observed that knowledge was good than attitude and practices with the score of $34 \%$ for knowledge, $18 \%$ for attitude and $13 \%$ for practices (Figure 1).

\section{Knowledge}

The overall knowledge score suggested that $34 \%$ (132) participants had good knowledge, $42 \%$ (167) had average and $24 \%$ (95) had poor knowledge regarding lifestyle disorders (Table 1). We observed that participants had adequate knowledge about obesity, smoking, alcohol consumption as risk factors for lifestyle disorders and poor knowledge regarding prevention of lifestyle disorders with the help of exercise, yoga, meditation. The present study also observed that the participants were aware about the common symptoms of various lifestyle disorders like stroke, cardiovascular diseases, diabetes, hypertension and cirrhosis. This study showed that more than half of the participants answered right to the questions based on psychological stress, environmental factors.

It was observed that the participants below the age group of 32 years had better knowledge when compared to those above 32 years. In the age group of $20-32$ years,36\% had good knowledge, $41 \%$ average and $23 \%$ participants had poor knowledge regarding lifestyle disorders (Figure 2). In the age group between 33 - 45 years, $32 \%$ had good knowledge, $43 \%$ had average and $25 \%$ had poor knowledge regarding lifestyle disorders (Figure 3). This study states that the younger population had better understanding and knowledge regarding risk factors, common symptoms and causes of lifestyle disorders.

\section{Attitude}

The overall attitude of participants towards lifestyle disorder was moderate. Out of 394 , only 70 participants had positive attitude, 203 participants had average attitude and remaining 121 participants were in the category of poor attitude towards lifestyle disorder (Table 1). This study showed that participants below the age of 32 years had better attitude regarding lifestyle disorders than the other group. While comparing both the age groups, In 20 - 32 years age group, 21 $\%$ had good attitude, $51 \%$ had average and $28 \%$ had poor attitude while the age group between 32 - 45 years, $15 \%$ had good, $52 \%$ had average and $33 \%$ had poor attitude towards lifestyle disorders (Figure 2 and 3). We observed that half of the participants agreed that lifestyle disorders are preventable and reversible. While assessment of their preferable option for any disorder, we found that half of the population gave more preference to medication rather than daily exercise and nutritious diet to control diabetes. Out of overall population half of the participants showed negligence towards reading nutrition facts, this reveals that the participants were giving less importance to ingredients in the packed food. Many people considered that skipping meal is better way of losing weight than exercising daily. Thus, it shows that participants are giving less importance to active lifestyle.

\section{Practices}

The practices followed by participants indicated that $13 \%$ (61) were following correct practices, $50 \%$ (174) belonged to average and $37 \%$ (174) were following poor practices (Table 1). The participants in the age group of below 32 years showed that $18 \%$ were following good practices and $64 \%$ were in average category in contrast to the participants in age group of above 32 years, only $13 \%$ were under the category of good. Therefore, we can conclude that age group above 32 years needs to be more aware about the healthy habits which they can incorporate in their lifestyle (Figure 2 and 3). The current study showed that among 394 participants, half of the population was exercising regularly in different forms like jogging, walking, etc. However, few habits like being inactive or sitting for long hours is been increased in this population less than half of participants are inactive for more than $7-8$ hours in a day due to long working hours, sedentary lifestyle, etc. This will have a negative impact on their health as this can lead to obesity. In terms of diet, participants were aware about the significance of fruits and vegetables intake, as nearly half of the participants were consuming vegetables and fruits daily. Furthermore, the number of participants that took fried food, snacks, carbonated drinks and fast food was also high, more than half of the population was taking fast food every day. Fried food and carbonated drinks are not good for health as oily food increases cholesterol levels and accumulation of fat in the body and leads to overweight or obesity. Thus, we concluded that even though the participants had adequate knowledge about lifestyle disorders, they were not following healthy practices because of their lifestyle. So, it is necessary to increase awareness regarding healthy practices. Lifestyle modification is very important to reduce impact of lifestyle disorders.

\section{CONCLUSIONS}

Above study concluded that the rural population had adequate knowledge about lifestyle disorders, but they lack in positive 
attitude and healthy practices towards lifestyle disorders. The study also signifies that the productive age group of the country was more involved in following unhealthy lifestyle habits.

Data sharing statement provided by the authors is available with the full text of this article at jemds.com.

Financial or other competing interests: None.

Disclosure forms provided by the authors are available with the full text of this article at jemds.com.

We would like to thank our university, Krishna Institute of Medical Sciences (Deemed to Be University) Karad, for allowing and promoting us to conduct this study. We express our gratitude towards our Dean Dr. G. Varadharajulu for constant support and help throughout our project. We would also like to thank all the participants for actively participating in this study.

\section{REFERENCES}

[1] Tabish SA. Lifestyle diseases: consequences, characteristics, causes and control. Journal of Cardiology \& Current Research 2017;9(3):1-4.

[2] Habib SH, Saha S. Burden of non-communicable disease: global overview. Diabetes \& Metabolic Syndrome: Clinical Research \& Reviews 2010;4(1):41-7.

[3] Upadhyay RP. An overview of the burden of noncommunicable diseases in India. Iran J Public Health 2012;41(3):1-8.

[4] Kanase SB, Varadharajulu G. Effect of task related training versus conventional training on walking performances in post stroke patients. Age (Years) 2012;(54):53.
[5] Razdan S, Koul RL, Motta A, et al. Cerebrovascular disease in rural Kashmir, India. Stroke 1989;20(12):1691-3.

[6] Madhura SJ, Suraj BK. Comparative analysis of associated risk factors amongst young and old stroke survivors. Indian Journal of Forensic Medicine \& Toxicology 2020;14(3):345-9.

[7] Mukhra R, Kaur T, Krishan $K$, et al. Overweight and obesity: a major concern for health in India. Clin Ter 2018;169(5):e199-201.

[8] Patterson JM, Garwick AW. The impact of chronic illness on families: a family systems perspective. Annals of Behavioral Medicine 1994;16(2):131-42.

[9] Thakur J, Prinja S, Garg CC, et al. Social and economic implications of non-communicable diseases in India. Indian J Community Med 2011;36(Suppl 1):S13-22.

[10] Engelgau MM, Karan A, Mahal A. The economic impact of non-communicable diseases on households in India. Global Health 2012;8(1):9.

[11] Perry CK, Rosenfeld AG, Kendall J. Rural women walking for health. West J Nurs Res 2008;30(3):295-316.

[12] Gautham M, Binnendijk E, Koren R, et al. First we go to the small doctor: first contact for curative health care sought by rural communities in Andhra Pradesh \& Orissa, India. Indian J Med Res 2011;134(5):627-38.

[13] Muhamad R, Yahya R, Yusoff HM. Knowledge, attitude and practice on cardiovascular disease among women in North-Eastcoast Malaysia. International Journal of Collaborative Research on Internal Medicine \& Public Health 2012;4(1):85-98. 